\title{
Management of Antenatally Detected Kidney Malformations
}

\author{
Angela Yulia ${ }^{1}$, Paul Winyard ${ }^{1,2}$ \\ ${ }^{1}$ Fetal Medicine Unit, Elizabeth Garrett Anderson Hospital, University College Hospitals London, \\ Huntley Street, London WC1N 6AU, UK. \\ ${ }^{2}$ Nephro-Urology Group, Developmental Biology and Cancer programme, University College London \\ Great Ormond Street Institute of Child Health, 30 Guildford Street, London WC1N 1EH, UK.
}

\begin{abstract}
Congenital anomalies of the kidneys and the urinary tract (CAKUT) are one of the most common sonographically identified antenatal malformations. Dilatation of the renal pelvis accounts for the majority of cases, but this is usually mild rather than an indicator of obstructive uropathy. Other conditions such as small through large hyperechogenic and/or cystic kidneys present a significant diagnostic dilemma on routine scanning. Accurate diagnosis and prediction of prognosis is often not possible without a positive family history, although maintenance of adequate amniotic fluid is usually a good sign.
\end{abstract}

Both pre- and postnatal genetic screening is possible for multiple known CAKUT genes but less than a fifth of non-syndromic sporadic cases have detectable monogenic mutations with current technology. In utero management options are limited, with little evidence of benefit from shunting of obstructed systems or installation of artificial amniotic fluid. Often outcome hinges on associated cardiac, neurological or other abnormalities, particularly in syndromic cases. Hence, management centres on a careful assessment of all anomalies and planning for postnatal care.

Early delivery is rarely indicated since this exposes the baby to the risks of prematurity in addition to their underlying CAKUT. Parents value discussions with a multidisciplinary team including fetal medicine and paediatric nephrology or urology, with neonatologists to plan perinatal care and clinical geneticists for future risks of CAKUT.

\section{Keywords:}

Prenatal ultrasound, CAKUT, LUTO, dysplastic, multicystic, polycystic, hyperechogenic, bright, hydronephrosis, renal dysplasia. 


\section{Introduction}

Congenital abnormalities of the genitourinary tract are the most common sonographically identified malformations, with an incidence of approximately 1 to 4 per 1,000 pregnancies (1). These represent $15-20 \%$ of all prenatally diagnosed congenital anomalies (2). The majority of cases have mild dilatation of the renal pelvis and a good outcome (3) but they tend to get aggregated into the 'obstructive uropathy' group with more severe bilateral pelvis and bladder dilatation secondary to lower urinary tract obstruction, typically posterior urethral valves in boys (4). Intrinsic renal abnormalities such as kidneys which are abnormally small or large, 'bright' or contain cysts may be sporadic but management should seek possible aetiologies including aneuploidy, genetic syndromes and genetically inherited renal disease.

Bilateral dysplastic kidneys can cause Potter's sequence with early death from pulmonary hypoplasia (5). For survivors, they are the most frequent cause of chronic renal failure in childhood, accounting for $25 \%$ of children requiring renal replacement therapy according to the latest Renal Registry produced by the UK Renal Association (6). Other CAKUT, such as obstructive uropathy and reflux nephropathy are linked to renal dysplasia, and these account for $15 \%$ and $7 \%$, respectively. Affected children might well have died in earlier times, but improvements in dialysis and transplantation (7) have improved survival and many now go on to have children, which is highly relevant for the genetic problems described elsewhere in this review.

Prenatal diagnosis allows appropriate counselling and improves the outcome of the affected children by better preparation for potential issues such as renal and respiratory insufficiency, and postnatal management and treatment of obstruction to prevent urinary tract infections, with further renal damage. With the introduction of modern ultrasound screening programs, about $60 \%$ of children having surgery for renal or urinary tract problems in their first five years of life are identified by prenatal ultrasound (8).

\section{Dilatation of the renal pelvis}

The commonest abnormality seen in the urinary tract antenatally is mild dilatation of one or both renal pelves. This is easily picked up by ultrasound because of the contrast between fluid and the kidney parenchyma. Traditionally, an antero-posterior renal pelvis size of over $4 \mathrm{~mm}$ before 28 weeks gestation and $>7 \mathrm{~mm}$ thereafter has been regarded as abnormal. This is too sensitive since many normal fetuses fall within this range (9) and there is poor correlation with adverse outcome (10). Key features related to eventual need for surgery include progressive dilatation and involvement of the renal calyces; hence, prognosis is likely to be good if less than $10 \mathrm{~mm}$ without these features.

\section{Obstructive uropathy}

Major lower urinary tract obstruction (LUTO) affects approximately 1 in 5,000 pregnancies, almost always boys with posterior urethral valves (PUV) (11). This may be an underestimation given incomplete reporting of termination and intrauterine fetal demise (IUFD), plus delayed 
postnatal diagnosis (12). Severe LUTO is also potentially associated with Potter's sequence and increased perinatal morbidity because of abnormal lung development.

\section{Ultrasound findings}

Fetal LUTO results in progressive bladder neck hypertrophy, bladder wall thickening (greater than $2 \mathrm{~mm}$ ) and hydronephrosis (Figure 1) (13). Classical ultrasound characteristics of LUTO are enlarged bladder with bilateral hydroureteronephrosis, although effects are occasionally asymmetrical with one side virtually normal. The more severe forms are associated with oligothrough anhydramnios with presumed secondary renal dysplasia, as well as pulmonary hypoplasia. A diagnostic 'keyhole' sign is sometimes seen in PUV, indicating continuity between distended bladder and the dilated posterior urethra proximal to the valves. Caliectasis (dilation of renal calices) and ureterectasis (dilation of the ureter) occur in only 40 $50 \%$ of cases (14).

\section{Differential diagnoses}

The differential diagnoses of LUTO is highly dependent on gender $(15,16)$. In the male fetus the most likely diagnosis is PUV; however, other rare causes such as anterior urethral valves, megalourethra, megacystis-microcolon-hyperparastalsis syndrome, cloacal malformations, and prolapsing cecoureterocele are possible $(15,17)$. LUTO caused by PUV results from an obstructing membrane that impairs or obstructs urine outflow through the posterior urethra. Correcting the defect postnatally does not necessarily abrogate renal consequences with around a third progressing to end-stage renal disease eventually (18). In the female fetus, urethral atresia is the most common cause; however, persistent cloaca, caudal regression, and megacystis-microcolon-intestinal hypoperistalsis syndrome must be ruled out (16). A persistent cloaca generally presents with an enlarged bladder prior to 16 weeks gestation, and will often be accompanied by debris within the cloaca, and intraluminal calcifications within bowel loops (due to intestinal communication) $(19,20)$.

\section{Prenatal Management and prognosis}

Apart from imaging the whole urinary tract, initial evaluation of the fetus with suspected LUTO should clarify gender, seek evidence of any co-existing abnormalities and assess amniotic fluid volume. Diagnostic genetic evaluation is also important since over $10 \%$ of LUTO cases are associated with Trisomies 13,18, or $21(19,20)$, although there is no evidence of common genes that underlie a significant proportion of PUV (21). Monitoring should consist of serial assessment of the fetal anatomy and growth (2-4 weeks) searching for worsening pathology such as oligohydramnios, or renal parenchymal abnormalities hinting at dysplasia (22). Maintenance of a normal amniotic fluid volume generally implies milder disease.

The big question with LUTO is whether to intervene to improve drainage. The standard technique is insertion of a vesico-amniotic shunt: there is a suggestion that this increases long term survival but usually with very poor residual renal function $(23,24)$. One issue may be that the decision to intervene is often delayed whilst vesicocintesis is performed to check urinary electrolytes as an indicator of poor renal function (i.e. almost confirming it is already too late to preserve kidney function), whilst technical factors such as shunts falling out and/or 
becoming blocked may confound benefits. Some highly specialised centres now offer surgical ablation of the valves using fetal endoscopic surgery (25) but widescale results on complication rate and improvement in renal function are awaited. Another potential intervention that was previously popular is serial amnioinfusion $(26,27)$, in an attempt to boost lung development. Data on this is limited mainly to case reports; again it may improve survival but it does nothing to rescue renal function and all of these proceedures increase risk of premature delivery.

Many parents elect to terminate the pregnancy with LUTO, particularly if there are poor longterm prognostic factors such as early diagnosis (decreased gestational age), oligohydramnios, renal cysts, and the combination of oligohydramnios, cortical cysts, and echogenic kidneys (28). Multiprofessional counselling should be offered along with the option for genetic testing in these cases, as well as in those who elect to continue with the pregnancy. In the latter scenario, management depends on the severity of the condition and it is worth considering transfer of care to tertiary centres with high-level Neonatal support and Paediatric Nephrology services.

\section{Structural kidney malformations}

There are a multiple genetic and non-genetic causes of renal abnormalities and a comprehensive list is beyond the scope of this review where we focus predominantly on dysplastic and polycystic kidneys.

\section{Dysplastic Kidneys}

Dysplastic kidneys are abnormally developed kidneys with a reduced number of poorly differentiated nephrons, increased stroma and, occasionally, cysts and metaplastic tissues, such as cartilage. Dysplastic kidneys can be any size, ranging between massive kidneys comprising multiple large cysts up to $9 \mathrm{~cm}$ in diameter, which are commonly termed 'multicystic dysplastic kidneys' (MCDK), to normal or small kidneys, with or without cysts. Unilateral dysplastic kidneys occurs in approximately 1 in 3,000-5,000 fetuses, and bilateral in 1 in 10,000 fetuses (29).

While unilateral kidney dysplasia may be sporadic, the finding of bilateral dysplasia should raise suspicion of aneuploidy or inherited conditions (Table 1) (30). Prenatal detection of bilateral disease is more likely when there is reduced liquor volume because this is so readily apparent on sonography. The lower urinary tract should be carefully examined in all cases of presumed renal dysplasia because there is a strong association between dysplasia and flow impairment: multicystic dysplastic kidneys are classically attached to atretic ureters, renal dysplasia commonly develops in LUTO and many features of dysplasia can be generated by experimental urinary tract obstruction during development in animals (31-33).

Besides the conditions listed on Table 1, renal dysplasia can be part of a syndrome, such as Bardet-Biedl syndrome, VATER association, renal coloboma syndrome, prune belly syndrome, branchio-oto-renal dysplasia, renal-hepatic-pancreatic dysplasia (34-39). Bardet-Biedl 
syndrome is an autosomal recessive ciliopathy which results in retinal dystrophy, obesity, polydactyly, cognitive impairment, urogenital anomalies, and renal abnormalities as the main clinical features. Prenatal ultrasound findings include moderately enlarged hyperechogenic kidneys with absent corticomedullary differentiation, medullary cysts, normal amniotic fluid volume, postaxial polydactyly (40). The VATER association is defined as vertebral defect, anal atresia, tracheoesophageal fistula, and renal dysplasia. More cases of Meckel syndrome and VATER association than of the other syndromes have been reported (34).

\section{Ultrasound findings}

Typical antenatal presentation of dysplasia is large bright kidneys, with or without cysts, at the routine 20-week anomaly scan (Figure 2). Dysplastic kidneys may also be small, but there is ascertainment bias for larger ones, as they are easier to visualise and smaller kidneys may be masked by (or attributed to) technical difficulties (5). Uniformly echogenic kidneys without cysts are not an uncommon finding and the difficulty lies in determining whether it is a normal variant or an indicator of significant renal disease. The degree of abnormality is a key prognosticator, which can be addressed via the following questions:

- how abnormal is the size (i.e. outside fifth or 95th centiles, or within these limits)?

- how bright is the kidney? (i.e. just a mild increase when compared to surrounding tissues, such as the liver, or very striking)

- are cysts visible?

- are cysts multiple? (if 'yes' at 20 weeks, then it is more likely to be MCDK, because cysts are rarely detectable in the alternative major differential diagnosis, either of the polycystic kidney diseases, until much later in pregnancy)

- what is the liquor volume? (i.e. normal, mildly decreased, or anhydramnios; it should be noted that this may not be helpful for presumed unilateral disease, if the contralateral kidney has good function)

- are there other non-renal abnormalities, suggesting a syndrome? (5)

Some ultrasound features help to distinguish between different types of dysplasia. MCDK may have characteristic appearances comprising multiple, hypoechoic, non-communicating cysts with no identifiable normal renal parenchyma (5). The cysts are distributed randomly and the kidney is usually enlarged with an irregular outline lacking a normal renal pelvis (Figure 3). Bilateral severe dysplasia with small kidneys may be difficult to distinguish from renal agenesis because detailed examination is technically challenging with severe oligohydramnios or anhydramnios, and enlarged adrenals in the renal fossa can mimic small kidneys in renal agenesis (30). In bilateral disease, the bladder may not be visible, whereas it is usually normal in unilateral dysplasia, lower urinary tract pathology not withstanding. Differential diagnoses of cystic dysplastic kidneys includes upper urinary tract dilatation and other intra-abdominal causes of cystic masses. Colour Doppler assessment may be useful in determining the diagnosis since the renal artery is invariably small or absent in MCDK (30). It is important to note that the appearance of dysplastic kidneys may alter during pregnancy: most often there is an initial increase in size, followed by decrease in size as gestation progresses. Previous observation revealed that dysplastic kidneys may even disappear completely, both before and after birth $(41,42)$, implying that patients diagnosed with renal agenesis may have originally had dysplasia. 
If all the biometry and the kidneys measurements lie above the $95^{\text {th }}$ percentile then an overgrowth syndrome, such as Beckwith-Wiedeman, Perlman, Simpson-Golabi-Behmel syndromes (Table 1) should be suspected (5). Karyotyping should be offered, particularly where other anomalies are detected. Review by a clinical geneticist is crucial.

\section{Prenatal management}

Detection of dysplastic kidneys should prompt a detailed examination of the fetus to look for other structural abnormalities, as up to $35 \%$ may have extra-renal anomalies (43). These are more likely in fetuses with bilateral rather than unilateral MCDKD (43), thus chromosome analysis should be offered especially in the presence of bilateral lesion and/or other extrarenal structural abnormalities. Risks of chromosomal defects in isolated renal dysplasia are low: in a study of 102 cases with MCDK, ten had an abnormal karyotype but these all had extra-renal anomalies too (43). In unilateral presentation, $30-50 \%$ of kidneys contralateral to dysplastic kidneys are either structurally abnormal (duplex system, pelvi-ureteric obstruction, agenesis or ectopic) or affected by vesico-ureteric reflux (VUR) $(43,44)$. Ultrasound screening of parents and siblings may be helpful since there have been of autosomal dominant inheritance of aplasia, dysplasia and other urinary tract abnormalities including VUR, duplications and horseshoe kidneys (45).

Although the exact familial incidence of urinary tract disease is still not well understood, one large study over 30 years ago noted that there is up to $9 \%$ familial association in cases of bilateral agenesis/severe dysplasia (46). Some mutations have been associated with specific findings such as the TCF2/HNGF1beta gene with antenatal bright kidneys (47), but even this gene can cause multiple CAKUT phenotypes and there are no mutations that account for more than a tiny percentage of cases $(21,48-50)$. It is now believed that environmental and epigenetic factors may be equally important in CAKUT (51).

Some centres are increasingly using MRI as well as ultrasound to investigate abnormal fetal kidneys $(52,53)$. This improves diagnostic to $94 \%$ versus $85 \%$ for ultrasound, but this was not statistically significant and only conferred a diagnostic advantage when ultrasound was technically challenging due to maternal habitus or fetal position $(52,53)$.

It is important to confirm the diagnosis as soon as possible to fully inform the parents and allow them choice over continuing the pregnancy, but there often remains an element of uncertainty because the renal phenotype can evolve during pregnancy. Serial ultrasound scan every 4-6 weeks should be offered to patients to assess progression and update prognosis, preferably in a dedicated fetal medicine centre with renal and urology experts. One of the most important factors is whether dysplastic kidneys are isolated or associated with extrarenal anomalies. Outcome for isolated dysplastic kidneys depends on whether they are bilateral or unilateral, the presence of compensatory hypertrophy in contralateral kidney and whether there are abnormalities in the contralateral kidney $(5,30)$. Bilateral dysplasia has a very poor outlook, particularly if there is significant oligohydramnios and the rate of kidney growth falls across centiles or involutes completely during pregnancy. The assessment of the liquor volume is essential. There is no antenatal treatment to date which is effective in treating this condition in utero. If abnormalities are severe and parents elect for termination, 
or there is a perinatal death, it is vitally important to arrange an expert post-mortem examination with tissue for histology and DNA storage. At minimum, an external examination with high-resolution imaging and needle biopsy of the kidneys should be performed if full assessment is declined (54). Data from these procedures can be invaluable in assessment and counselling of genetic risk in affected families. In cases with severe disease where a perinatal death may occur, there should be good communication with the delivering team and their neonatologists to ensure that appropriate arrangements have been made for early assessment and initiation of either active management or palliative care, as appropriate to the situation and parental wishes.

\section{Outcome and prognosis}

Infants with severe bilateral kidney disease often die in the neonatal period as a consequence of the Potter's sequence (i.e. pulmonary hypoplasia secondary to inadequate renal function and amniotic fluid during pregnancy). It is technically feasible to perform peritoneal dialysis from birth, if fill volumes do not compromise breathing, and short term haemodialysis is now also available using bespoke small volume circuits and machines (55), but such interventions are technically challenging (30). Less severe bilateral dysplasia may also lead to chronic renal failure throughout childhood, but this becomes much easier to manage as children get bigger, not only because drug therapy and dialysis is technically easier, but also because most centres will consider renal transplants once the child has reached a weight of 9-10 kg (30).

Children with dysplasia should be referred to the regional paediatric nephrology centre so that further investigations and management can be instigated promptly. The likelihood of developing chronic renal failure in patients with bilateral dysplasia is difficult to predict before birth, and several earlier studies correlated early childhood renal function with long-term outcome and suggested that a calculated glomerular filtration rate (GFR) of $<15 \mathrm{ml} / \mathrm{min}$ per $1.73 \mathrm{~m}$ at 6 months, or $25 \mathrm{ml} / \mathrm{min}$ per $1.73 \mathrm{~m}$ at 18 months of age are associated with a worse prognosis $(56,57)$. However, most kidneys do seem to improve during the first three years and only then does renal function plateau or decrease, with poorer outcome if there is proteinuria (urine albumin/creatinine ratio $>200 \mathrm{mg} / \mathrm{mmol}$ ) more than two febrile urine infections, hypertension or initial eGFR $<40 \mathrm{ml} / \mathrm{min} / 1.73 \mathrm{~m}^{2}(58)$. Some unilateral dysplastic kidneys still have excretory capacity, thus a radionuclide scan may be useful to determine contribution to overall renal function. In most cases, however, function is dependent on the contralateral organ; compensatory hypertrophy would be expected for a truly 'normal' opposite kidney, versus impaired renal function if hypoplastic (30). All patients with only one functioning kidney have a substantial risk for hypertension, proteinuria, and progression to chronic kidney disease, hence renal function should be monitored and care taken to avoid potential renal injury (59). Historical studies suggested that dysplastic kidneys had a significant risk of neoplasia (60), but this was not confirmed in a systematic review (61) and elective nephrectomy therefore does not appear warranted unless there are other complications.

\section{Polycystic Kidney Disease}


In polycystic kidney disease (PKD), the early kidney development is unremarkable which differs from dysplasia where it is never normal and nephron number is intrinsically reduced (30). Subsequently, however, cysts develop which destroy normal surrounding renal tissue and lead to progressive kidney enlargement, with renal and extrarenal complications including hypertension, infection and chronic renal failure. There are two main forms of PKD: autosomal recessive and autosomal dominant PKD (ARPKD and ADPKD, respectively). Both can present antenatally although ARPKD tends to be more severe, potentially resulting in lifethreatening perinatal complications, and neither usually present with overt cysts; instead they are more likely to appear to be large bright kidneys antenatally (62). When cysts become detectable, there are usually numerous small cysts in ARPKD, compared with fewer, larger cysts in the dominant disease (30).

\section{Autosomal recessive polycystic kidney disease (ARPKD)}

ARPKD is a rare disorder, occurring approximately in 1:20,000 live births (63). A significant proportion of affected fetuses do not survive when they have severe oligohydramnios, and neonatal death may occur because of pulmonary hypoplasia. ARPKD is caused by mutations in the PKHD1 gene (polycystic kidney and hepatic disease gene) which is located on chromosome $6 p$, and this encodes for protein fibrocystin. Fibrocystin is typically expressed in the primary cilia and the basal body of renal and bile duct epithelial cells. The exact function is not well understood; but it is expected to act as a membrane receptor, interacting with extracellular protein ligands and transducing intracellular signals to the nucleus involved in collecting-duct and biliary differentiation (64).

Renal pathology in ARPKD is characterised by non-obstructive dilatation or ectasia of the collecting tubules located in the renal medulla, resulting in microcysts up to $2 \mathrm{~mm}$ in diameter. In severe cases, the cysts may expand into the cortex. Severity of the renal pathology appears directly related to the proportion of nephrons affected by cysts and correlated with type of PHKD1 mutation, with dual truncating mutations having the worst prognosis (65). Liver changes including bile duct proliferation with portal fibrosis are also invariably present (66).

\section{Ultrasound findings}

The predominant prenatal ultrasound presentation of ARPKD is uniform, massive enlargement of the kidneys with diffuse hyperechogenicity of both cortex and medulla, and loss of corticomedullary differentiation, presumably due to the numerous small cysts below the detection threshold for current ultrasound technology. This may be associated with oligohydramnios, particularly in early cases which have a poor prognosis. Hyperechogenicity of the kidneys has been demonstrated as early as $12-16$ weeks $(67,68)$, although, the ultrasound features of ARPKD can appear anytime during gestation. There is usually evidence of renal enlargement and increased echogenicity by 24 weeks gestation. Rarely, diagnosis may not be apparent until the third trimester or postnatally (69). ARPKD is associated with hepatic fibrosis but this rarely presents antenatally (70)

\section{Diagnosis}


ARPKD is not associated with an increased frequency of aneuploidy; thus, chromosome studies are not helpful, but can be useful for excluding other disorders in the differential diagnoses associated with an abnormal karyotype. In high-risk families and suspected diagnosis, molecular genetic diagnostic tests provide a useful adjunct to ultrasound for diagnosing ARPKD and these should be discussed with parents, particularly if planning further pregnancies which have a $25 \%$ chance of recurrence. MRI has also been used to diagnose ARPKD in utero (71), but this technique is not in regular use in most centres.

\section{$\underline{\text { Prognosis }}$}

The prognosis for prenatally diagnosed ARPKD is either very poor, with death in the neonatal period, or reasonable if they survive beyond this age. Poor outcome is expected in cases with early onset of ultrasonically detectable marked renal changes and severe oligohydramnios, whereas in cases with normal volume of amniotic fluid and moderately enlarged kidneys, there is a higher likelihood of survival without significant immediate morbidity (30). It is estimated that up to $40 \%$ infants may die from respiratory failure rather than renal problems, although this number cannot be precisely verified because of terminations where the diagnosis was not fully confirmed. Survivors beyond the neonatal period have a much better prognosis $(72,73)$ than the gloomy outlook in many textbooks which used to report progressive renal and hepatic failure, with death of the majority during childhood. In a large study of over 100 children, Zerres et al., reported that the 1-year survival probability after the first month was $94 \%$ for male patients and $82 \%$ for female patients (72), while the renal survival of $86 \%$ at 1 year and $67 \%$ at 15 years was described by another group (73). Besides declining renal function, the other major problems reported were urinary tract infections, severe systemic hypertension requiring multiple-drug therapy and hepatic fibrosis with portal hypertension leading to hypersplenism and gastrooesophageal varices. Age at diagnosis impacts on the age at end stage renal disease. In one cohort, $25 \%$ of patients who presented in the perinatal period required renal replacement therapy by 11 years (74).

\section{Obstetrics and Antenatal Management}

Once the diagnosis of ARPKD is made or suspected, the case should be managed by a multidisciplinary team consisting of fetal medicine subspecialists and midwives, paediatric renal specialist, neonatologist, and geneticist. Termination of pregnancy is an option where there are poor prognostic factors such as progressive oligo-/anhydramnios of massive nephromegaly. Otherwise, key indicators on follow-up in pregnancy are kidney size and echogenicity, and amniotic fluid volume. Given the high perinatal mortality and potential need for dialysis and renal transplant in the long-term, detailed discussion with parents regarding their preferences for aggressive perinatal treatment should occur. Although there is no published literature regarding optimal mode and time of delivery, this is usually planned at around 39 weeks gestation at a facility with tertiary neonatal intensive care capacity. It should be noted that there is increased risk of fetal distress secondary to cord compression during labour when there is oligo-/anhydramnios, hence elective Caesarean section should be discussed with families. 
Autosomal dominant polycystic kidney disease (ADPKD) is the commonest inherited renal cystic disease. ADPKD is much more common than ARPKD, affecting around 1 in 1,000 and it accounts for $7-10 \%$ of the adult dialysis population (75). Although the typical age of clinical symptoms is between the third to fifth decade of life (76), rarely ( $<1 \%$ of cases) ADPKD can present in utero or in the neonatal period, with ultrasound changes often similar to ARPKD (77). If ADPKD develops prenatally in a family, there is increased likelihood that further affected children will also present early (78). There are two major genes: mutations in the PKD1 (polycystic kidney disease 1) gene accounts for $85-90 \%$ of cases (79), and in PKD2 (polycystic kidney disease 2 ) for $10-15 \%$ of cases (80). Relatively rare mutations in Ganab cause a milder form of PKD (81).

Initial renal development is grossly normal in ADPKD, however, over decades there is slow development of large spherical cystic dilatation in all parts of the nephron. The cysts may be localised to the distal nephron and the collecting duct initially, but in later stages they are found throughout the cortex and medulla. As the cysts enlarge, they severely compromise the functional integrity of the remaining normal parenchyma. The renal pathology is focal with areas of abnormal nephrons scattered among areas of normal nephrons. The tubule wall, which is lined by a single layer of epithelial cells, expands and then rapidly closes off from the tubule of origin. This pathology is different from ARPKD in which cysts are derived from collecting tubules and remain connected to the nephron of origin (63).

\section{Ultrasound Findings}

Most ADPKD kidneys are reported as normal on antenatal ultrasound although, from our highly-specialised practice, we believe that some may have subtle undiagnosed abnormalities with equivocal increased echogencity. These would not be picked up at present without the family history of ADPKD and cutting edge ultrasound machines. Probably less than $2 \%$ of affected fetuses have a clear antenatal presentation with enlarged kidneys ( 1 to 2 standard deviations above the mean size for gestational age) and a hyperechogenic cortex (82). Cysts are rarely seen until after 30 weeks gestation (62) and, when seen, it is not unusual to see variability between kidneys and a mixture of small and large cysts corresponding to different stages of cystogenesis (Figure 5).

It is not always straightforward to distinguish AR and ADPKD on ultrasonographic appearance, but ADPKD is much more likely when overt cysts are observed (62) (83). Amniotic fluid volume is usually normal since normal nephrons are present; this is an important distinction from ARPKD. In a report of 27 prenatally diagnosed cases (82), amniotic fluid volume was normal in $89 \%$, slightly diminished in $7 \%$, and increased initially, but with secondary normalisation in one case (4\%) (82). Associated structural abnormalities, such as cysts in the liver and spleen, have not been identified prenatally.

\section{Diagnosis}

Prenatal ultrasound findings may hint at an ADPKD diagnosis or be fairly clear in a tiny fraction, as above, but the key additional information needed is family history. New mutations are rare, affecting only 1 out of 20 cases, so most will have a parent with cysts or a history of 
ADPKD in the family. When the mutation is known, invasive prenatal diagnosis using Chorionic-Villous Sampling from 11 weeks, or amniocentesis from 15 weeks, is the method of choice for parents who seek a definitive diagnosis in utero (5). Preimplantation genetic diagnosis is offered in some centres, particularly with preceding severe cases, but it is contentious for the majority who are relatively unaffected until middle age (84). Intriguingly, some cases previously ascribed to ARPKD with severe perinatal presentation are now known to be caused by inheriting two hypomorphic ADPKD alleles (85). Risks to the mother should also be considered during pregnancy, since hypertensive mothers with ADPKD have a high risk for fetal and maternal complications and require close monitoring to prevent the development of pre-eclampsia (86).

Renal hyperechogenicity can vary in appearance during the clinical course of ADPKD. In 1998, Jeffery et al., described a case of a PKD1 gene carrier with hyperechogenic renal enlargement on serial fetal ultrasounds at 21, 23 and 34 weeks of gestation, who subsequently had normal sized kidneys and corticomedullary differentiation after birth (87). Later on, the diagnosis of ADPKD was confirmed in this infant when cysts developed at 11 months of age in one kidney and 20 months in the other. We have seen multiple similar cases with abnormal antenatal scans (often subtle hyperechogenicity as above) ollowed by a normal/equivocal scan in infancy, then progressive cyst development in childhood (personal communication PJDW).

ADPKD is associated with a normal karyotype; therefore, chromosome studies are not useful for confirming the diagnosis. The disease is unknown to the family in over $50 \%$ of parents at the time of obstetric ultrasound. If fetal ADPKD is suspected but there is not a family history of the condition, then parents where should have a renal ultrasound - if positive for cysts then ADPKD is the likely diagnosis (although clinical picture can be confounded with young parents because some adults don't develop cysts until their 30s (88)).

\section{Prognosis}

Currently, there are no large, single-centre studies which report the prognosis for fetuses diagnosed with ADPKD in utero. However, it is very rare for children with ADPKD to develop chronic renal failure before adulthood $(89,90)$ aside from those severely affected before birth who may have complex mutations as above, with worse prognosis akin to antenatal ARPKD (91). For ADPKD diagnosed in childhood, the largest study reports 312 children followed for up to 15 years (89): children with higher blood pressure and severe renal enlargement at a young age continued to experience faster renal growth long term. The same group also reported benefits of controlling blood pressure and statin therapies $(92,93)$. Taken together, these studies strongly suggest that the prognosis for prenatally diagnosed ADPKD is excellent in childhood unless there is oligo-/anhydramnios.

\section{Obstetrics and Antenatal Management}

Once the diagnosis is suspected or confirmed, serial ultrasound surveillance scans between 4 to 6 weekly is recommended to observe the appearance, size and echogenicity of kidneys and 
the amount of liquor volume. If stable, this condition should not affect the time, mode, and place of delivery. The baby will need to be referred to paediatric nephrologist for follow up. The case should be managed by multidisciplinary team consisting of fetal medicine subspecialists and midwives, paediatric nephrologist, neonatologist, and geneticist. Appropriate counselling should take place in order to prepare the parents regarding the short and long-term prognosis of the condition and $50 \%$ recurrence risk.

\section{Conclusions}

There is a wide range of underlying pathology associated with renal malformations which can be detected on prenatal ultrasound. Some of these, such as mild renal pelvis dilatation, do not have significant postnatal consequences and we may be doing our patients a disservice by overdiagnosing them. Others such as LUTO, renal dysplasia and polycystic kidney diseases can have major effects on renal function, however, and early diagnosis facilitates counselling and appropriate management to optimise outcome.

\section{$\underline{\text { References }}$}

1. Grandjean $\mathrm{H}$, Larroque $\mathrm{D}$, Levi $\mathrm{S}$. The performance of routine ultrasonographic screening of pregnancies in the Eurofetus Study. American journal of obstetrics and gynecology. 1999;181(2):44654.

2. Elder JS. Antenatal hydronephrosis. Fetal and neonatal management. Pediatric clinics of North America. 1997;44(5):1299-321.

3. Nef S, Neuhaus TJ, Sparta G, Weitz M, Buder K, Wisser J, et al. Outcome after prenatal diagnosis of congenital anomalies of the kidney and urinary tract. European journal of pediatrics. 2016;175(5):667-76.

4. Hindryckx A, De Catte L. Prenatal diagnosis of congenital renal and urinary tract malformations. Facts, views \& vision in ObGyn. 2011;3(3):165-74.

5. Winyard $P$, Chitty LS. Dysplastic kidneys. Seminars in fetal \& neonatal medicine. 2008;13(3):142-51.

6. Lewis M, Shaw J, Reid C, Evans J, Webb N, Verrier-Jones K. Demography and management of childhood established renal failure in the UK (chapter 13). Nephrology, dialysis, transplantation : official publication of the European Dialysis and Transplant Association - European Renal Association. 2007;22 Suppl 7:vii165-75.

7. Rees L. Management of the infant with end-stage renal failure. Nephrology, dialysis, transplantation : official publication of the European Dialysis and Transplant Association - European Renal Association. 2002;17(9):1564-7.

8. Bhide A, Sairam S, Farrugia MK, Boddy SA, Thilaganathan B. The sensitivity of antenatal ultrasound for predicting renal tract surgery in early childhood. Ultrasound in obstetrics \& gynecology : the official journal of the International Society of Ultrasound in Obstetrics and Gynecology. 2005;25(5):489-92.

9. Chitty LS, Altman DG. Charts of fetal size: kidney and renal pelvis measurements. Prenatal diagnosis. 2003;23(11):891-7.

10. Hothi DK, Wade AS, Gilbert R, Winyard PJ. Mild fetal renal pelvis dilatation: much ado about nothing? Clinical journal of the American Society of Nephrology : CJASN. 2009;4(1):168-77.

11. Farrugia MK WA. Congenital urinary bladder outlet obstruction. Fetal and Maternal Medicine Review 2010;21:155-73. 
12. Morris RK, Malin GL, Quinlan-Jones E, Middleton LJ, Diwakar L, Hemming K, et al. The Percutaneous shunting in Lower Urinary Tract Obstruction (PLUTO) study and randomised controlled trial: evaluation of the effectiveness, cost-effectiveness and acceptability of percutaneous vesicoamniotic shunting for lower urinary tract obstruction. Health technology assessment (Winchester, England). 2013;17(59):1-232.

13. Anumba DO, Scott JE, Plant ND, Robson SC. Diagnosis and outcome of fetal lower urinary tract obstruction in the northern region of England. Prenatal diagnosis. 2005;25(1):7-13.

14. Bernardes LS, Aksnes G, Saada J, Masse V, Elie C, Dumez Y, et al. Keyhole sign: how specific is it for the diagnosis of posterior urethral valves? Ultrasound in obstetrics \& gynecology : the official journal of the International Society of Ultrasound in Obstetrics and Gynecology. 2009;34(4):419-23.

15. Ruano R, Sananes N, Sangi-Haghpeykar H, Hernandez-Ruano S, Moog R, Becmeur F, et al. Fetal intervention for severe lower urinary tract obstruction: a multicenter case-control study comparing fetal cystoscopy with vesicoamniotic shunting. Ultrasound in obstetrics \& gynecology : the official journal of the International Society of Ultrasound in Obstetrics and Gynecology. 2015;45(4):452-8.

16. Morris RK, Middleton L, Malin GL, Quinlan-Jones E, Daniels J, Khan KS, et al. Outcome in fetal lower urinary tract obstruction: a prospective registry study. Ultrasound in obstetrics \& gynecology : the official journal of the International Society of Ultrasound in Obstetrics and Gynecology. 2015;46(4):424-31.

17. Denny E, Quinlan-Jones E, Bibila S, Kilby M. The experience of pregnant women with a diagnosis of fetal lower urinary tract obstruction (LUTO). Midwifery. 2014;30(6):636-42.

18. Hennus PM, van der Heijden GJ, Bosch JL, de Jong TP, de Kort LM. A systematic review on renal and bladder dysfunction after endoscopic treatment of infravesical obstruction in boys. PloS one. 2012;7(9):e44663.

19. Ruano R, Duarte S, Bunduki V, Giron AM, Srougi M, Zugaib M. Fetal cystoscopy for severe lower urinary tract obstruction--initial experience of a single center. Prenatal diagnosis. 2010;30(1):309.

20. Ruano R. Fetal surgery for severe lower urinary tract obstruction. Prenatal diagnosis. 2011;31(7):667-74.

21. van der Ven AT, Vivante A, Hildebrandt F. Novel Insights into the Pathogenesis of Monogenic Congenital Anomalies of the Kidney and Urinary Tract. Journal of the American Society of Nephrology : JASN. 2018;29(1):36-50.

22. Lissauer D, Morris RK, Kilby MD. Fetal lower urinary tract obstruction. Seminars in fetal \& neonatal medicine. 2007;12(6):464-70.

23. Morris RK, Malin GL, Quinlan-Jones E, Middleton L, Hemming K, Burke D, et al. Percutaneous vesicoamniotic shunting versus conservative management for fetal lower urinary tract obstruction (PLUTO): a randomised trial. Lancet (London, England). 2013;382(9903):1496-506.

24. Nassr AA, Shazly SAM, Abdelmagied AM, Araujo Junior E, Tonni G, Kilby MD, et al. Effectiveness of vesicoamniotic shunt in fetuses with congenital lower urinary tract obstruction: an updated systematic review and meta-analysis. Ultrasound in obstetrics \& gynecology : the official journal of the International Society of Ultrasound in Obstetrics and Gynecology. 2017;49(6):696-703.

25. Martinez JM, Masoller N, Devlieger R, Passchyn E, Gomez O, Rodo J, et al. Laser ablation of posterior urethral valves by fetal cystoscopy. Fetal diagnosis and therapy. 2015;37(4):267-73.

26. Galati V, Beeson JH, Confer SD, Frimberger D, Campbell JB, Ramji FG, et al. A favorable outcome following 32 vesicocentesis and amnioinfusion procedures in a fetus with severe prune belly syndrome. Journal of pediatric urology. 2008;4(2):170-2.

27. Bienstock JL, Birsner ML, Coleman F, Hueppchen NA. Successful in utero intervention for bilateral renal agenesis. Obstetrics and gynecology. 2014;124(2 Pt 2 Suppl 1):413-5.

28. Matsell DG, Yu S, Morrison SJ. Antenatal Determinants of Long-Term Kidney Outcome in Boys with Posterior Urethral Valves. Fetal diagnosis and therapy. 2016;39(3):214-21.

29. Woolf AS, Winyard PJ. Advances in the cell biology and genetics of human kidney malformations. Journal of the American Society of Nephrology : JASN. 1998;9(6):1114-25. 
30. Winyard P, Chitty L. Dysplastic and polycystic kidneys: diagnosis, associations and management. Prenatal diagnosis. 2001;21(11):924-35.

31. Beck AD. The effect of intra-uterine urinary obstruction upon the development of the fetal kidney. The Journal of urology. 1971;105(6):784-9.

32. Attar R, Quinn F, Winyard PJ, Mouriquand PD, Foxall P, Hanson MA, et al. Short-term urinary flow impairment deregulates PAX2 and PCNA expression and cell survival in fetal sheep kidneys. The American journal of pathology. 1998;152(5):1225-35.

33. Peters CA, Carr MC, Lais A, Retik AB, Mandell J. The response of the fetal kidney to obstruction. The Journal of urology. 1992;148(2 Pt 2):503-9.

34. Chen RY, Chang H. Renal dysplasia. Archives of pathology \& laboratory medicine. 2015;139(4):547-51.

35. Shimada K, Matsumoto F, Matsui F, Obara T. Retrovesical cystic lesions in female patients with unilateral renal agenesis or dysplasia. International journal of urology : official journal of the Japanese Urological Association. 2010;17(6):570-8.

36. Chaturvedi KU, Singh B. Renal dysplasia with multisystem malformation--a study of 9 cases. Indian journal of pediatrics. 1989;56(3):393-7.

37. Mori M, Matsubara K, Abe E, Matsubara Y, Katayama T, Fujioka T, et al. Prenatal diagnosis of persistent cloaca associated with VATER (vertebral defects, anal atresia, tracheo-esophageal fistula, and renal dysplasia). The Tohoku journal of experimental medicine. 2007;213(4):291-5.

38. Melnick M, Hodes ME, Nance WE, Yune H, Sweeney A. Branchio-oto-renal dysplasia and branchio-oto dysplasia: two distinct autosomal dominant disorders. Clinical genetics. 1978;13(5):42542.

39. Li Y, Manaligod JM, Weeks DL. EYA1 mutations associated with the branchio-oto-renal syndrome result in defective otic development in Xenopus laevis. Biology of the cell. 2010;102(5):27792.

40. Garcia-Tizon Larroca S, Blagoeva Atanasova V, Orera Clemente M, Aluja Mendez A, Ortega Abad V, Perez Fernandez-Pacheco R, et al. Prenatal diagnosis of Bardet-Biedl syndrome in a case of hyperechogenic kidneys: Clinical use of DNA sequencing. Clinical case reports. 2017;5(4):449-53.

41. Rickwood AM, Anderson PA, Williams MP. Multicystic renal dysplasia detected by prenatal ultrasonography. Natural history and results of conservative management. British journal of urology. 1992;69(5):538-40.

42. Rottenberg GT, Gordon I, De Bruyn R. The natural history of the multicystic dysplastic kidney in children. The British journal of radiology. 1997;70(832):347-50.

43. Lazebnik N, Bellinger MF, Ferguson JE, 2nd, Hogge JS, Hogge WA. Insights into the pathogenesis and natural history of fetuses with multicystic dysplastic kidney disease. Prenatal diagnosis. 1999;19(5):418-23.

44. Atiyeh B, Husmann D, Baum M. Contralateral renal abnormalities in patients with renal agenesis and noncystic renal dysplasia. Pediatrics. 1993;91(4):812-5.

45. Srivastava T, Garola RE, Hellerstein S. Autosomal dominant inheritance of multicystic dysplastic kidney. Pediatric nephrology (Berlin, Germany). 1999;13(6):481-3.

46. Roodhooft AM, Birnholz JC, Holmes LB. Familial nature of congenital absence and severe dysgenesis of both kidneys. The New England journal of medicine. 1984;310(21):1341-5.

47. Decramer S, Parant O, Beaufils S, Clauin S, Guillou C, Kessler S, et al. Anomalies of the TCF2 gene are the main cause of fetal bilateral hyperechogenic kidneys. Journal of the American Society of Nephrology : JASN. 2007;18(3):923-33.

48. Hwang DY, Dworschak GC, Kohl S, Saisawat P, Vivante A, Hilger AC, et al. Mutations in 12 known dominant disease-causing genes clarify many congenital anomalies of the kidney and urinary tract. Kidney international. 2014;85(6):1429-33.

49. Kohl S, Hwang DY, Dworschak GC, Hilger AC, Saisawat P, Vivante A, et al. Mild recessive mutations in six Fraser syndrome-related genes cause isolated congenital anomalies of the kidney and urinary tract. Journal of the American Society of Nephrology : JASN. 2014;25(9):1917-22. 
50. Vivante A, Hwang DY, Kohl S, Chen J, Shril S, Schulz J, et al. Exome Sequencing Discerns Syndromes in Patients from Consanguineous Families with Congenital Anomalies of the Kidneys and Urinary Tract. Journal of the American Society of Nephrology : JASN. 2017;28(1):69-75.

51. Nicolaou N, Renkema KY, Bongers EM, Giles RH, Knoers NV. Genetic, environmental, and epigenetic factors involved in CAKUT. Nature reviews Nephrology. 2015;11(12):720-31.

52. Liu HD, Yu H, Zhao JG, Xu XF, Wang NF, Wang W, et al. [Value of MRI in prenatal diagnosis of abnormal fetal kidneys]. Zhonghua fu chan ke za zhi. 2016;51(12):895-900.

53. Cassart M, Massez A, Metens T, Rypens F, Lambot MA, Hall M, et al. Complementary role of MRI after sonography in assessing bilateral urinary tract anomalies in the fetus. AJR American journal of roentgenology. 2004;182(3):689-95.

54. Thayyil S, Sebire NJ, Chitty LS, Wade A, Chong W, Olsen O, et al. Post-mortem MRI versus conventional autopsy in fetuses and children: a prospective validation study. Lancet (London, England). 2013;382(9888):223-33.

55. Coulthard MG, Crosier J, Griffiths C, Smith J, Drinnan M, Whitaker M, et al. Haemodialysing babies weighing $<8 \mathrm{~kg}$ with the Newcastle infant dialysis and ultrafiltration system (Nidus): comparison with peritoneal and conventional haemodialysis. Pediatric nephrology (Berlin, Germany). 2014;29(10):1873-81.

56. Ismaili K, Schurmans T, Wissing KM, Hall M, Van Aelst C, Janssen F. Early prognostic factors of infants with chronic renal failure caused by renal dysplasia. Pediatric nephrology (Berlin, Germany). 2001;16(3):260-4.

57. Van Dyck $M$, Sidler S, Proesmans W. Chronic renal failure in infants: effect of strict conservative treatment on growth. European journal of pediatrics. 1998;157(9):759-62.

58. Gonzalez Celedon C, Bitsori M, Tullus K. Progression of chronic renal failure in children with dysplastic kidneys. Pediatric nephrology (Berlin, Germany). 2007;22(7):1014-20.

59. Westland R, Schreuder MF, van Goudoever JB, Sanna-Cherchi S, van Wijk JA. Clinical implications of the solitary functioning kidney. Clinical journal of the American Society of Nephrology : CJASN. 2014;9(5):978-86.

60. Dimmick JE, Johnson HW, Coleman GU, Carter M. Wilms tumorlet, nodular renal blastema and multicystic renal dysplasia. The Journal of urology. 1989;142(2 Pt 2):484-5; discussion 9.

61. Narchi H. Risk of hypertension with multicystic kidney disease: a systematic review. Archives of disease in childhood. 2005;90(9):921-4.

62. Gimpel C, Avni FE, Bergmann C, Cetiner M, Habbig S, Haffner D, et al. Perinatal Diagnosis, Management, and Follow-up of Cystic Renal Diseases: A Clinical Practice Recommendation With Systematic Literature Reviews. JAMA pediatrics. 2018;172(1):74-86.

63. Wilson PD. Polycystic kidney disease. The New England journal of medicine. 2004;350(2):151-

64.

64. Ward CJ, Hogan MC, Rossetti S, Walker D, Sneddon T, Wang X, et al. The gene mutated in autosomal recessive polycystic kidney disease encodes a large, receptor-like protein. Nature genetics. 2002;30(3):259-69.

65. Denamur E, Delezoide AL, Alberti C, Bourillon A, Gubler MC, Bouvier R, et al. Genotypephenotype correlations in fetuses and neonates with autosomal recessive polycystic kidney disease. Kidney international. 2010;77(4):350-8.

66. Jung G, Benz-Bohm G, Kugel H, Keller KM, Querfeld U. MR cholangiography in children with autosomal recessive polycystic kidney disease. Pediatric radiology. 1999;29(6):463-6.

67. Reuss A, Wladimiroff JW, Niermeyer MF. Sonographic, clinical and genetic aspects of prenatal diagnosis of cystic kidney disease. Ultrasound in medicine \& biology. 1991;17(7):687-94.

68. Bronshtein M, Bar-Hava I, Blumenfeld Z. Clues and pitfalls in the early prenatal diagnosis of 'late onset' infantile polycystic kidney. Prenatal diagnosis. 1992;12(4):293-8.

69. Wisser J, Hebisch G, Froster U, Zerres K, Stallmach T, Leumann E, et al. Prenatal sonographic diagnosis of autosomal recessive polycystic kidney disease (ARPKD) during the early second trimester. Prenatal diagnosis. 1995;15(9):868-71. 
70. Gunay-Aygun M, Font-Montgomery E, Lukose L, Tuchman Gerstein M, Piwnica-Worms K, Choyke P, et al. Characteristics of congenital hepatic fibrosis in a large cohort of patients with autosomal recessive polycystic kidney disease. Gastroenterology. 2013;144(1):112-21.e2.

71. Kaneko S, Satoh Y, Ikemura K, Konishi T, Ohji T, Karasaki Y, et al. Alterations of expression of the cytoskeleton after immortalization of human fibroblasts. Cell structure and function. 1995;20(1):107-15.

72. Zerres K, Rudnik-Schoneborn S, Deget F, Holtkamp U, Brodehl J, Geisert J, et al. Autosomal recessive polycystic kidney disease in 115 children: clinical presentation, course and influence of gender. Arbeitsgemeinschaft fur Padiatrische, Nephrologie. Acta paediatrica (Oslo, Norway : 1992). 1996;85(4):437-45.

73. Roy S, Dillon MJ, Trompeter RS, Barratt TM. Autosomal recessive polycystic kidney disease: long-term outcome of neonatal survivors. Pediatric nephrology (Berlin, Germany). 1997;11(3):302-6.

74. Gunay-Aygun M, Font-Montgomery E, Lukose L, Tuchman M, Graf J, Bryant JC, et al. Correlation of kidney function, volume and imaging findings, and PKHD1 mutations in 73 patients with autosomal recessive polycystic kidney disease. Clinical journal of the American Society of Nephrology : CJASN. 2010;5(6):972-84.

75. Simms RJ. Autosomal dominant polycystic kidney disease. BMJ (Clinical research ed). 2016;352:i679.

76. Johnson AM, Gabow PA. Identification of patients with autosomal dominant polycystic kidney disease at highest risk for end-stage renal disease. Journal of the American Society of Nephrology : JASN. 1997;8(10):1560-7.

77. Cole BR, Conley SB, Stapleton FB. Polycystic kidney disease in the first year of life. The Journal of pediatrics. 1987;111(5):693-9.

78. Zerres K, Rudnik-Schoneborn S, Deget F. Childhood onset autosomal dominant polycystic kidney disease in sibs: clinical picture and recurrence risk. German Working Group on Paediatric Nephrology (Arbeitsgemeinschaft fur Padiatrische Nephrologie. Journal of medical genetics. 1993;30(7):583-8.

79. The polycystic kidney disease 1 gene encodes a $14 \mathrm{~kb}$ transcript and lies within a duplicated region on chromosome 16. The European Polycystic Kidney Disease Consortium. Cell. 1994;77(6):88194.

80. Mochizuki T, Wu G, Hayashi T, Xenophontos SL, Veldhuisen B, Saris JJ, et al. PKD2, a gene for polycystic kidney disease that encodes an integral membrane protein. Science (New York, NY). 1996;272(5266):1339-42.

81. Porath B, Gainullin VG, Cornec-Le Gall E, Dillinger EK, Heyer CM, Hopp K, et al. Mutations in GANAB, Encoding the Glucosidase Ilalpha Subunit, Cause Autosomal-Dominant Polycystic Kidney and Liver Disease. American journal of human genetics. 2016;98(6):1193-207.

82. Brun M, Maugey-Laulom B, Eurin D, Didier F, Avni EF. Prenatal sonographic patterns in autosomal dominant polycystic kidney disease: a multicenter study. Ultrasound in obstetrics \& gynecology : the official journal of the International Society of Ultrasound in Obstetrics and Gynecology. 2004;24(1):55-61.

83. Chung EM, Conran RM, Schroeder JW, Rohena-Quinquilla IR, Rooks VJ. From the radiologic pathology archives: pediatric polycystic kidney disease and other ciliopathies: radiologic-pathologic correlation. Radiographics : a review publication of the Radiological Society of North America, Inc. 2014;34(1):155-78.

84. De Rechter S, Kringen J, Janssens P, Liebau MC, Devriendt K, Levtchenko E, et al. Clinicians' attitude towards family planning and timing of diagnosis in autosomal dominant polycystic kidney disease. PloS one. 2017;12(9):e0185779.

85. Vujic M, Heyer CM, Ars E, Hopp K, Markoff A, Orndal C, et al. Incompletely penetrant PKD1 alleles mimic the renal manifestations of ARPKD. Journal of the American Society of Nephrology : JASN. 2010;21(7):1097-102. 
86. Chapman AB, Johnson AM, Gabow PA. Pregnancy outcome and its relationship to progression of renal failure in autosomal dominant polycystic kidney disease. Journal of the American Society of Nephrology : JASN. 1994;5(5):1178-85.

87. Jeffery S, Saggar-Malik AK, Economides DL, Blackmore SE, MacDermot KD. Apparent normalisation of fetal renal size in autosomal dominant polycystic kidney disease (PKD1). Clinical genetics. 1998;53(4):303-7.

88. Pei $Y$, Obaji J, Dupuis A, Paterson AD, Magistroni R, Dicks E, et al. Unified criteria for ultrasonographic diagnosis of ADPKD. Journal of the American Society of Nephrology : JASN. 2009;20(1):205-12.

89. Fick-Brosnahan GM, Tran ZV, Johnson AM, Strain JD, Gabow PA. Progression of autosomaldominant polycystic kidney disease in children. Kidney international. 2001;59(5):1654-62.

90. Mekahli D, Woolf AS, Bockenhauer D. Similar renal outcomes in children with ADPKD diagnosed by screening or presenting with symptoms. Pediatric nephrology (Berlin, Germany). 2010;25(11):2275-82.

91. MacDermot KD, Saggar-Malik AK, Economides DL, Jeffery S. Prenatal diagnosis of autosomal dominant polycystic kidney disease (PKD1) presenting in utero and prognosis for very early onset disease. Journal of medical genetics. 1998;35(1):13-6.

92. Cadnapaphornchai MA, McFann K, Strain JD, Masoumi A, Schrier RW. Increased left ventricular mass in children with autosomal dominant polycystic kidney disease and borderline hypertension. Kidney international. 2008;74(9):1192-6.

93. Cadnapaphornchai MA, George DM, McFann K, Wang W, Gitomer B, Strain JD, et al. Effect of pravastatin on total kidney volume, left ventricular mass index, and microalbuminuria in pediatric autosomal dominant polycystic kidney disease. Clinical journal of the American Society of Nephrology : CJASN. 2014;9(5):889-96. 
Table 1. Conditions associated with large and echogenic kidneys

\begin{tabular}{|c|c|c|c|c|c|c|c|c|}
\hline & $\begin{array}{l}\text { Liquo } \\
\text { r } \\
\text { Volu } \\
\text { me }\end{array}$ & $\begin{array}{c}\text { Ren } \\
\text { al } \\
\text { Cyst } \\
\text { s }\end{array}$ & $\begin{array}{c}\text { Renal } \\
\text { Pelvic } \\
\text { Dilatati } \\
\text { on }\end{array}$ & $\begin{array}{c}\text { Ren } \\
\text { al } \\
\text { Size }\end{array}$ & $\begin{array}{c}\text { Macroso } \\
\text { mia }\end{array}$ & $\begin{array}{c}\text { Extrarenal } \\
\text { abnormalit } \\
\text { ies }\end{array}$ & $\begin{array}{c}\text { Inheritan } \\
\text { ce }\end{array}$ & $\begin{array}{l}\text { Alternati } \\
\text { ve } \\
\text { Prenatal } \\
\text { Diagnosi } \\
\text { s }\end{array}$ \\
\hline Obstruction & $\begin{array}{l}\text { N/Olig } \\
\mathrm{o}\end{array}$ & $+/-$ & + & + & - & $+/-$ & Sporadic & - \\
\hline Dysplasia & $\begin{array}{l}\text { N/Olig } \\
0\end{array}$ & $+/-$ & $+/-$ & + & - & $+/-$ & $10 \% A D$ & - \\
\hline ARPKD & $\begin{array}{l}\text { N/Olig } \\
0\end{array}$ & - & - & + & - & - & $A R$ & DNA \\
\hline ADPKD & $\begin{array}{l}\text { N/Olig } \\
\mathrm{o}\end{array}$ & + & - & + & - & - & $A D$ & DNA \\
\hline $\begin{array}{l}\text { Beckwith- } \\
\text { Wiedeman }\end{array}$ & $\begin{array}{l}\text { N/Pol } \\
y\end{array}$ & - & $+/-$ & + & + & + & $\begin{array}{l}\text { AD or } \\
\text { Disomy }\end{array}$ & $\begin{array}{l}\text { Cyto/DN } \\
\text { A }\end{array}$ \\
\hline Perlman & $\begin{array}{l}\text { N/Olig } \\
\text { o }\end{array}$ & - & $+/-$ & + & + & + & $A R$ & - \\
\hline $\begin{array}{l}\text { Simpson- } \\
\text { Golabi- } \\
\text { Behmel }\end{array}$ & $?$ & $?$ & $?$ & + & + & + & X-linked & DNA \\
\hline $\begin{array}{l}\text { Meckel } \\
\text { Gruber }\end{array}$ & Oligo & - & - & + & - & + & $A R$ & DNA \\
\hline $\begin{array}{l}\text { Nephrocalcin } \\
\text { osis }\end{array}$ & $\mathrm{N}$ & - & - & - & - & - & Sporadic & - \\
\hline
\end{tabular}

ARPKD, Autosomal recessive (infantile) polycystic kidney disease; ADPKD, autosomal dominant (adult) polycystic kidney disease;

$\mathrm{N}$, normal; $A D$, autosomal dominant; $A R$, autosomal recessive; Cyto, cytogenetics; Oligo, oligohydramnios; Poly, polyhydramnios;

DNA, molecular tests. 